\title{
A HERMENÊUTICA DE WILHEIM DILTHEY E A REFLEXÃO EPISTEMOLÓGICA NAS CIÊNCIAS HUMANAS CONTEMPORÂNEAS
}

\author{
Jovanka Baracuhey Cavalcanti Scocuglia*
}

\begin{abstract}
Resumo: Este artigo ressalta a contribuição de Wilheim Dilthey, dentro da chamada "hermenêutica romântica" alemã, para as ciências humanas contemporâneas, sobretudo quanto à sua busca dos fundamentos filosóficos e epistemológicos de uma forma de conhecimento científico alternativo ao conhecimento "positivista" e "naturalista". Parte-se de três pontos principais: o primeiro é o significado dos termos "Verstehen" e "Hermenêutica" dentro da perspectiva de Dilthey; o segundo refere-se aos principais conceitos de sua teorização como, por exemplo, "experiência interna e externa", "causalidade" e "compreensão", identificando duas fases na sua compreensão da ação humana, onde ele passa de uma etapa marcada pela compreensão psicológica, à outra, mais centrada na compreensão hermenêutica. E, para finalizar, tecem-se algumas considerações sobre a contribuição de Dilthey para as ciências sociais e sobre a crítica central de Gadamer à forma como ele buscou uma objetividade para as ciências humanas. Considera-se que o conceito de experiência, a concepção de causalidade e a busca de uma objetividade para as ciências humanas, nos termos colocados por Dilthey, sugeriram várias perspectivas ao debate filosófico desde a segunda metade do século XX, como, por exemplo, Gadamer e sua hermenêutica filosófica, ou, ainda, autores mais recentes como Giddens (1977) e Souza Santos (1989), preocupados em desenvolver
\end{abstract}

* Docente e pesquisadora do Departamento de Arquitetura e Urbanismo da Universidade Federal da Paraíba (UFPB), credenciada junto ao Programa Regional de Pós-Graduação em Desenvolvimento e Meio Ambiente (PRODEMA/UFPB) e ao Programa de PósGraduação em Sociologia da UFPB; mestre em Ciências Sociais; doutora em Sociologia pela Universidade Federal de Pernambuco.

Artigo recebido em 7 maio 2003; aprovado, 30. agost. 2003. 
esta abordagem metodológica para as ciências humanas, sobretudo, na direção do surgimento das condições fundamentais para uma mudança de paradigmas.

Palavras-chave: hermenêutica, epistemologia, experiência, compreensão histórica, causalidade.

\section{Introdução}

Este trabalho discute, fundamentalmente, a tentativa de Wilheim Dilthey, em fins do século XIX e início do século XX, dentro da chamada "hermenêutica romântica" alemã, de estabelecer diferenças entre a lógica do conhecimento nas ciências naturais e nas ciências humanas. ${ }^{1}$ Dilthey buscava os fundamentos filosóficos e epistemológicos de uma forma de conhecimento científico alternativo ao conhecimento "positivista" e "naturalista". Suas idéias eram bem sintonizadas com as preocupações e discussões teóricas do final do século. Nas palavras de Dilthey:

As ciências que têm a realidade sócio-histórica como seu objeto de estudo buscam, mais intensamente do que antes, as relações sistemáticas entre elas e com os seus fundamentos. Condições dentro de várias ciências positivas estão operando nesta direção, associadas às forças poderosas originadas a partir dos motins na sociedade, desde a Revolução Francesa. O conhecimento das forças que governam a sociedade, das causas que têm produzido estas revoluções e dos recursos da sociedade para promover o progresso saudável, tem se tornado uma preocupação vital de nossa civilização. Conseqüentemente, relativas às ciências naturais, é crescente a importância das ciências que lidam com a sociedade. (Dilthey, 1989, p. 56)

Dilthey, que analisou a causalidade na história criticando a visão positivista e a empiricista, afirmava não ser possível no campo das "ciências do espírito" (Geissenswissenchaften) ou das ciências humanas, se falar em "leis gerais", questionava o próprio conceito de "causa", pois, para ele, esse conceito implicava a idéia de necessidade e inexorabilidade - sendo mais correto pensar-se em termos de "motivos", de "desejos" para explicar situações de mudança. 
Deste modo, pode-se dizer que uma questão subjacente à abordagem anti-naturalista de Dilthey é: como a compreensão dos significados pode ser elevada ao mesmo nível de clareza metodológica característico das ciências da natureza? Quais são os métodos que permitem uma leitura objetiva das estruturas simbólicas de qualquer tipo, incluindo ações, práticas sociais, normas e valores? Esta problemática refere-se, portanto, a uma busca de cientificidade para as ciências interpretativas, numa época em que as ciências da natureza avançavam rapidamente.

O conceito filosófico central era, sobretudo, o conceito de explicação (Erklärung) e evidenciava-se a distinção, nas ciências sociais e na história, entre explicar (Erklären) as ações e as crenças humanas e compreender (Verstehen) seus significados. A partir disto, duas abordagens se diferenciavam quanto ao estudo da ação humana. Uma abordagem "positivista", que investia na compreensão de significados apenas como uma reconstrução imaginativa das intenções ou propósitos dos atores. O aspecto científico, mais próximo da verdade, no estudo da ação seria a possibilidade de construção de hipóteses explicativas que deveriam ser incorporadas às teorias gerais sobre o comportamento humano e verificadas ou testadas através de métodos seguros de observação empírica. Acreditava-se que o resultado seria a unificação das ciências, numa estrutura única para os diversos campos de pesquisa. Tal estrutura seria a identificação de sequiências regulares de comportamento e a possibilidade de formulação de leis universais e de teorias para, através delas, predizer ou explicar a ocorrência dos eventos. De outro lado, na abordagem interpretativa, os teóricos da "Verstehen" e da "Hermenêutica" argumentavam que as ciências sociais e a história não poderiam ser adaptadas à lógica das ciências naturais porque a compreensão interpretativa tem um papel diferente nas ciências. E, assim, compreender uma dada ação ou credo é um trabalho científico que precede a explicação do porquê da ocorrência da ação. Seria um trabalho de leitura da situação, de análise do contexto ao qual a ação ou crença pertencem, compreendendo-as sob a ótica de outras ações e crenças historicamente constituídas. A construção de hipóteses explicativas e seus testes empíricos, se tornariam problemas de 
interpretação dependentes de uma pressuposição específica de como é o evento a ser explicado e, portanto, de como ter acesso ao significado (Warnke, 1987, p. 7).

Os trabalhos de Dilthey foram produzidos entre 1870 e 1910, sendo Introduction to the Human Sciences (1883) o primeiro trabalho sistemático. Esta obra de Dilthey é um exame filosófico das ciências humanas, caracterizado em sua dedicatória como uma 'Crítica da Razão Histórica'. É considerado, por Makkreel e Rodi (1989, p. 3), como o primeiro trabalho em que Dilthey descreve, em detalhes, a importância de distinguir as ciências humanas das ciências naturais. Para os referidos autores (1989, p. 4-5), Dilthey foi visto primeiramente como um historiador sensível da cultura, não apenas por suas críticas literárias, mas, também, por sua valorosa contribuição para a história da filosofia, sobretudo, pela descoberta das primeiras idéias de Hegel. Outros estudos relevantes elaborados por Dilthey são: Ideas Concerning a Descritive and Analytical Psychology e The Formation of the Historical World in the Human Sciences (1910), além de uma série de estudos intermediários.

As idéias seqüentes estão estruturadas em três pontos principais: o primeiro ponto é o significado dos termos "Verstehen" e "Hermenêutica" dentro da perspectiva da chamada "hermenêutica romântica" de Dilthey; o segundo ponto refere-se aos principais conceitos de sua teorização como "experiência interna e externa", "causalidade", identificando duas fases na sua compreensão da ação humana, onde ele passa de uma etapa marcada pela compreensão psicológica, a outra, mais centrada na compreensão hermenêutica. E, para finalizar, algumas considerações sobre a contribuição de Dilthey para as ciências sociais e sobre a crítica central de Gadamer à forma como Dilthey buscou uma objetividade para as ciências humanas.

\section{"Verstehen" e "Hermenêutica"}

O uso do termo hermenêutica remonta ao século XVII e está associado ao problema da compreensão e/ou interpretação dos 
significados de textos, sinais, símbolos, práticas sociais, ações históricas e formas de arte. Mas, enquanto disciplina distinta, a hermenêutica tem suas origens no século XIX com os esforços, sobretudo de Scheiermacher e, posteriormente, de Dilthey, no sentido da formulação de uma teoria da interpretação, ampliando o alcance da compreensão hermenêutica do campo teológico, dos textos clássicos, para a compreensão objetiva de qualquer tipo de texto e/ou expressão humana. Para Dilthey, a teoria hermenêutica poderia ser considerada a base para as ciências humanas ou Geisteswissenschaften, um modo de acesso privilegiado ao significado em geral.

Em Verdade e Método, Gadamer (1998, p. 273-274) distingue dois caminhos diversos nos quais se desenvolveu, inicialmente, a doutrina da arte da compreensão e da interpretação: o teológico e o filológico. No primeiro caminho, ligado ao contexto teológico, a hermenêutica designava a arte de se compreender o conteúdo verdadeiro da Bíblia e se alicerçava no sentido unívoco que deveria ser interpretado por ela mesma, numa relação circular do todo e das partes. No segundo caminho, a partir do século XVIII, a hermenêutica libertou-se dos enquadramentos dogmáticos e passou a ser também utilizada pela filologia, como a arte de se compreender a literatura clássica e, pela jurisprudência, como a arte de se compreender as leis do direito. Assim, já não existia nenhuma diferença entre a interpretação dos textos sagrados e profanos e, portanto, só haveria uma hermenêutica que acabaria sendo não só uma "arte de interpretação correta das fontes escritas" como, também, uma atividade da historiografia.

Como afirma Hamlin,

... a partir do século XIX, alguns teóricos alemães da chamada Escola Histórica estenderam a idéia de compreensão para o domínio da história: a hermenêutica passou a designar o método da interpretação dos produtos históricos, tornando-se, assim, um método relativo ao que hoje se conhece por ciências sociais. Esta fase da hermenêutica é normalmente conhecida como hermenêutica romântica, pelas relações estreitas da Escola Histórica com o romantismo alemão. Já no século 


\begin{abstract}
XX, a hermenêutica assume um caráter mais filosófico, no sentido de que compreender e interpretar não deve ser considerado apenas como empreendimento metodológico, e portanto relativo à ciência, mas como algo que diz respeito ao todo da experiência dos seres humanos no mundo, experiência esta que tem na linguagem uma dimensão fundamental. (Hamlin,1999, p. 1).
\end{abstract}

Desse modo, pode-se identificar, ainda, duas abordagens hermenêuticas complementares: uma mais preocupada com afirmar a importância das ciências humanas frente às ciências naturais, procurando liberar a interpretação dos dogmas, na busca de uma compreensão ou "Verstehen" metodologicamente segura; e, a outra, com preocupações mais filosóficas, atribuindo maior centralidade ao papel da linguagem como fenômeno universal de interação e de compreensão, tendo como maior representante Hans-Georg Gadamer e Martin Heidegger. Estes últimos, consideravam a interpretação hermenêutica como um processo anterior a toda investigação científica, vislumbrando a possibilidade de mediação entre a linguagem da ciência e a linguagem utilizada pelos atores sociais na vida cotidiana. Reivindicavam, assim, uma noção de "objetividade" diferente, criticando tanto a noção de compreensão "objetiva" das ciências naturais quanto a própria visão que se desenvolveu na história da hermenêutica romântica.

A perspectiva de Dilthey aproxima-se mais da primeira abordagem, pois se desenvolveu a partir da busca de uma forma de conhecimento independente dos métodos das ciências naturais, um método compreensivo relativo às ciências humanas, sem paralelos nas ciências da natureza.

O problema da relação das ciências humanas com nosso conhecimento da natureza só pode ser resolvido quando nós resolvermos a oposição na qual começamos, ou seja, entre um ponto de vista transcendental para o qual a natureza está sujeita às condições da consciência e o ponto de vista empírico objetivista que vê o desenvolvimento do espírito humano como sujeito às condições da natureza (...). A condição de tal solução seria uma demonstração da realidade objetiva da experiência interior e a prova da existência de um mundo externo a partir do qual nós podemos concluir, então, que este mundo contêm fatos humanos e significados espirituais por meio de um processo de 
transferência de nossa vida interior para dentro deste mundo, uma inferência analógica. ( Dilthey, 1989, p. 71) .

É, portanto, a partir desta separação entre ciências humanas e ciências da natureza que pode-se compreender o sentido geral atribuído ao termo "Verstehen", antes de analisar-se os fundamentos filosóficos e metodológicos compreensivos desenvolvidos por Dilthey.

De um modo geral, o termo "Verstehen" designaria uma atividade conceitual específica às ciências sociais ou humanas em contraposição ao termo explicação ou "Erklären" das ciências da natureza. A doutrina do "Verstehen" teria seu fundamento numa suposta diferença entre mente e tudo que não é mente, que Hamlin (1999, p. 2) afirma ser um desenvolvimento da velha distinção filosófica entre mente e matéria, que foi assumindo um papel importante à medida que se formaram as diversas disciplinas que se constituíram, depois, nas ciências sociais.

Há distintas abordagens interpretativas nas ciências sociais, como a sociologia de Max Weber, a fenomenologia de Alfred Schutz, a dramaturgia de Ervin Goffman, o idealismo lingüístico de Peter Winch, a hermenêutica crítica de Jürgen Habermas, entre outros. Essas teorias compreensivas reforçam o dualismo ontológico, pois centralizam suas investigações na singularidade do mundo social em relação ao natural e reafirmam a maior complexidade das análises das ações humanas. Reforçam, também, um dualismo epistemológico, pois consideram que são realidades completamente diferentes, não podendo ser estudadas da mesma maneira porque os interesses cognitivos que orientam o conhecimento são distintos. Para Dilthey, por exemplo, as ciências sociais se interessam pelas singularidades enquanto as ciências naturais se interessam pela generalidade, pelo que se repete ou pelo que não varia.

Esta discussão do caráter científico das ciências sociais compreensivas está presente em todos os hermeneutas românticos, em especial, em Dilthey. O início da hermenêutica romântica, por sua vez, está associado às tentativas, durante o século XIX, de autores como Schleiermacher, Ranke, Droysen e Dilthey, de construir uma 
teoria da interpretação. Gadamer (1998, p. 277) identifica a contribuição destes autores com o começo da virada em direção à consciência histórica, "o desvencilhar-se de todos os enquadramentos dogmáticos e liberar-se a si mesma para elevarse ao significado universal de um organon histórico”, ainda no século XVIII.

Em Verdade e Método (1998), Gadamer analisa o processo de formação da ciência hermenêutica moderna, como um momento de inflexão, de surgimento de um novo sentido para a compreensão e para a própria reflexão teórica. Não se trata de uma doutrina da arte a serviço da atividade do filólogo ou do teólogo, mas uma busca de alcançar uma fundamentação teórica do procedimento comum a teólogos e filólogos, uma vez que, para além de ambos os interesses, remonta a uma relação mais originária da compreensão do pensamento. Schleiermacher, por sua vez, teria determinado a idéia de uma hermenêutica universal a partir da visão de que a experiência da alteridade e da possibilidade do mal-entendido são universais, ou seja, o esforço de compreensão é maior cada vez que não se dá uma compreensão imediata e cada vez que se tem de contar com a possibilidade de um mal-entendido. O objetivo é, então, evitar o malentendido.

Outro elemento da visão de Schleiermacher que é importante para se entender Dilthey, refere-se ao que deve ser compreendido: não é apenas a literalidade das palavras e seu sentido objetivo, mas também a individualidade de quem fala e, conseqüentemente, do autor. Sendo necessário retroceder à gênese das idéias e, dessa forma, paralelamente à interpretação gramatical viria a interpretação psicológica - que foi um dos elementos determinantes para a formação das idéias de Dilthey.

Para os hermeneutas românticos, em especial Schleiermacher, todo discurso é arte, e é, também, o compreender. A arte de compreender, a hermenêutica, como uma inversão de um ato de fala, a "pós-construção de uma construção" (Gadamer,1998, p. 294), ou seja, a hermenêutica como uma espécie de inversão da retórica e da poética. E, assim, Schleiermacher amplia a utilização do método de 
interpretação hermenêutico, tanto para textos quanto para diálogos e obras de arte bíblicos ou profanos, e estabelece uma mudança no objetivo da compreensão.

Neste sentido, o foco da compreensão, para Schleiermacher, não se localiza na veracidade do que está sendo dito, mas na sua individualidade enquanto pensamento de uma pessoa em particular, expressa num contexto particular e num tempo específico. Mas, para que se compreenda a individualidade de quem fala, Schleiermacher acreditava que se deve retroceder até a gênese das idéias, na qual a totalidade da linguagem e, portanto, da cultura, desempenha um papel fundamental.

A ênfase na compreensão de produtos mentais individuais trouxe à tona, então, uma nova preocupação: a compreensão psicológica - que não se refere ao conhecimento de uma psicologia experimental, baseada em leis do comportamento, mas a uma "psicologia descritiva", de acordo com a qual a mente, a sociedade e os processos históricos são aspectos de um domínio psíquico geral.

Contudo, embora esta perspectiva tenha sido iniciada por Schleiermacher e trabalhada por Ranke e Droysen, Gadamer (1998, p. 335) reconhece que a ampliação da hermenêutica romântica - até fazer dela uma historiografia e até uma teoria do conhecimento das "ciências do espírito" -, foi obra de Dilthey. Segundo Gadamer, uma reflexão clara e metódica sobre isso não se encontra em Ranke, nem em Droysen, mas em Dilthey. Ele elaborou um análise lógica do conceito de "nexos" na história que representou a ampliação do princípio hermenêutico, segundo o qual as partes individuais de um texto só podem ser entendidas a partir do todo, e este somente a partir daquelas (o chamado 'círculo hermenêutico'), sobre o mundo da história. Não somente as fontes chegam a nós como textos, mas também a realidade histórica é em si um texto que deve ser compreendida. ${ }^{2}$

Deste prisma, o questionamento epistemológico tem em Dilthey um começo diferente. Pois, o que sustenta a construção do mundo histórico não são fatos extraídos da experiência e em seguida incluídos numa referência valorativa (como fizeram os neo-kantianos), mas o 
fato de que a sua base é, antes, a historicidade interna, própria da experiência. As ciências históricas continuam o pensamento começado na experiência da vida. Não precisam começar pelo fundamento da possibilidade de que nossos conceitos coincidam com o "mundo exterior", porque o mundo histórico de cujo conhecimento se trata em Dilthey é sempre um mundo formado e conformado pelo espírito humano. E aqui, segundo Gadamer (1998, p. 340), ele remonta a Vico que já havia afirmado o primado epistemológico do mundo da história feito pelo homem. Ou seja, o que torna possível o conhecimento histórico é a homogeneidade de sujeito e objeto.

Mas, para Dilthey a questão seria mais propriamente: como se eleva a experiência do indivíduo e seu conhecimento à experiência histórica? Dilthey procura desenvolver o modo como o indivíduo adquire um contexto vital e, a partir daí, quais os conceitos constitutivos que podem sustentar, também, o contexto histórico e seu conhecimento.

Ver-se-á, a seguir, como Dilthey faz isto, ainda trabalhando com suas idéias desenvolvidas em Introduction to the Human Sciences (1883), onde ele busca explicitar os fundamentos ontológicos e epistemológicos das ciências humanas em contraposição aos das ciências naturais, estabelecendo que as diferenças se dão tanto em seus objetos de estudo quanto em suas metodologias. As diferenças metodológicas são vistas como derivadas da distinção ontológica entre os objetos de conhecimento de ambas ciências.

\section{Dilthey - da compreensão psicológica à compreensão hermenêutica}

Em Introduction to the Human Sciences (1883), Dilthey parte da preocupação em estabelecer os fundamentos filosóficos das ciências humanas (Geisteswissenschaften) e em fazer uma "Crítica da Razão Histórica”. Embora rejeitasse a metafísica, como o faziam Kant e, também, os positivistas, não aceitava as ciências naturais como um modelo para orientar as ciências humanas. Dilthey considerava que 
as ciências naturais podiam apenas explicar (Erklären) eventos observados relacionando-os com outros eventos em consonância com as leis da natureza e que essas leis não dizem nada quanto à natureza interior das coisas e dos processos estudados. Para ele, há nos seres humanos um sentido oculto por trás de suas ações observáveis, algo interno, que possibilita a compreensão (Verstehen) das ações humanas em termos de pensamentos, sentimentos e desejos. Há possibilidade de conhecer não apenas o que um homem faz, mas as experiências (Erlebnisse), as memórias e julgamentos de valor que o levaram a agir de tal ou qual forma.

Neste sentido, o conhecimento nesse campo não é, como nas ciências naturais, meramente fenomenal e externo. Há transições nas quais as percepções levam aos pensamentos, esses aos sentimentos e esses, por sua vez, aos desejos e às ações. Tais conexões constituem as "estruturas" da personalidade individual e o entendimento delas é também a chave para o entendimento maior dos processos históricos. É porque os homens se comunicam uns com os outros que suas experiências podem despertar pensamentos e sentimentos e levar a ações da parte de outros e, então, o padrão "estrutural" individual ramifica-se e torna-se o padrão de vida de grupos sociais, de nações e de civilizações. A história seria um processo contínuo de interações desse tipo e para entender um evento particular ou ação ou expressão deveríamos vê-las nesse tipo de contexto.

A oposição entre substância material e mental foi recolocada pela diferença entre os mundos internos e externos - o mundo externo como dado na percepção externa (sensação) através dos sentidos, e o mundo interno como apresentado originalmente através da apreensão interna dos eventos e atividades físicas (reflexão). Assim, nesta formulação, o problema está na possibilidade de tratamento empírico. As experiências que não poderiam ser expressões científicas adequadas na substância da doutrina da psicologia racional são, agora, validadas à luz de métodos novos e melhores. (Dilthey, 1989, p. 60)

Para Dilthey, os homens vivem em condições que não podem ser formuladas em leis gerais, seja da psiquê humana ou de grupos sociais. Os homens são inteligíveis para nós como indivíduos e nos interessam justamente por causa de sua individualidade e 
singularidade. A vida humana é mais complexa e possui mais aspectos do que os fenômenos da natureza, uma vez que todas as experiências humanas e atividades são atravessadas por escolhas, preferências, valores, julgamentos. Conseqüentemente, as ciências humanas devem, também, constituir um corpo de disciplinas mais variado e mais dividido, o qual nenhum método ou princípio pode governar. As ciências humanas seriam, assim, dependentes da habilidade dos pesquisadores para entender o padrão "estrutural" da experiência e, a partir daí, ver o comportamento humano do interior.

É, neste sentido, que Gabriel Cohn (1979, p. 15-16) ressalta três tensões que articulam o pensamento de Dilthey: 1) o mundo histórico (criado pelos seres humanos) e o mundo natural (independente ou externo aos seres humanos); 2) explicação dos fenômenos naturais a partir do exterior e compreensão interna dos fenômenos humanos; e, 3) o estudo segmentado e atomístico da realidade natural e a apreensão integradora das experiências vividas das ciências humanas/do espírito.

O trecho de uma carta enviada por Dilthey a um alto funcionário do Ministério da Educação da Prússia - Friedrich Althoff - revela, em parte, estas oposições e sua concepção de como a filosofia relaciona-se com a ciência:

Toda ciência, toda filosofia é experimental. Toda experiência deriva sua coerência e sua correspondente validade do contexto da consciência humana. A discussão entre o idealismo e o realismo pode ser resolvida através da análise psicológica, a qual pode demonstrar que o mundo real dado na experiência não é um fenômeno na minha representação; é muito mais dado para mim como algo distinto de mim mesmo, porque eu sou um ser que não representa meramente, mas que também deseja e sente. O mundo real é o que o desejo possui na reflexão consciente quando isto encontra resistência ou quando a mão sente pressão. Essa consciência reflexiva do desejo é tanto do mundo real quanto de si próprio. Ambos self e mundo real são, portanto, dados na totalidade da vida psíquica. Cada um existe em relação com o outro e são igualmente imediatos e verdadeiros. (Dilthey,1882, p.493-94 apud Makkreel \& Rodi, 1989, p.7-8).

Pode-se dizer, assim, que a concepção de Dilthey da abordagem filosófica da ciência começa com o conceito de experiência, embora 
ele não aceite o empiricismo. Ele caracteriza sua abordagem como empírica mais do que empiricista. Isto significa que a filosofia deve começar com experiências que são imediatamente dadas, nomeadas, fatos da consciência, mas não pode explicar esses fatos da consciência em termos de suas gêneses ou em termos de qualquer mecanismo causal, como fazem os empiricistas. Ao invés disto, a filosofia deve apreender esses fatos da consciência como dados últimos do ponto de vista da experiência e da "investigação empírica sem preconceitos" - esta investigação, em Dilthey, é "analítica-descritiva" e tenta evitar não apenas as explicações causais do empiricismo, mas, também, as especulações da metafísica (Makkreel \& Rodi, 1989:8).

Dilthey procura resolver o conflito entre idealismo e realismo através de um tipo de psicologia filosófica que analisa os fatos da consciência. Dilthey indica que o que é analisado é a realidade de toda a experiência humana. Quando ele vai definir as ciências humanas como Geisteswissenschaften (ciências do espírito) aponta para alguns dos problemas na utilização deste termo, pois o termo espírito (Geist) pode dar uma indicação imperfeita do objeto central destas ciências, uma vez que as ciências humanas, como ele as compreende, não devem separar "os fatos do espírito humano das unidades psicofísicas da natureza humana". Ou seja, para ele, os homens seriam "unidades de vida" e a vida mental dos homens seriam parte da "unidade de vida psicofísica" - que seria a forma pela qual a vida humana se manifesta (Dilthey, 1989, p. 51-67).

Assim, a análise psicológica, como concebida por Dilthey, começa com a totalidade da vida psíquica e articula as funções cognitivas, emocionais e voluntaristas operando nela. O pensamento cognitivo e representacional não podem ser isolados do resto da vida psíquica.

Nem sangue verdadeiro corre nas veias do sujeito do conhecimento construído por Locke, Hume e Kant, mas sim o extrato diluído da razão como uma mera atividade do pensamento. Uma abordagem histórica, assim como uma abordagem psicológica do ser humano como um todo, leva-me a explicar até mesmo o conhecimento e seus conceitos (tais como mundo externo, tempo, substância e causa) em 
termos dos múltiplos poderes de um ser que deseja, sente e pensa; e faço isto apesar do fato de que o conhecimento pareça ser tecido através de conceitos derivados a partir de meros conteúdos de percepção, representação e pensamento. (Dilthey, 1989, p. 50).

Dilthey vê a relação de desejo como central para a fundamentação da ciência, especialmente para as ciências humanas. Embora resista, o desejo é imediatamente sentido como uma realidade independente. Com base nessa experiência torna-se possível diferenciar um self real da realidade do mundo exterior. As duas realidades: self e mundo - são os pólos primordiais da totalidade da vida psíquica.

Além disto, Dilthey acredita que usando este método, relacionando todo componente do pensamento abstrato científico com a natureza do ser humano, do modo como ela se revela na experiência, no estudo da linguagem e da história, buscando as conexões entre estes componentes, ele alcançaria uma visão do conhecimento da realidade na qual nossa própria personalidade (como uma unidade de vida), o mundo externo, outros indivíduos, suas vidas temporais e suas interações, poderiam ser explicados em termos desta totalidade da natureza humana. E, mais:

No processo da vida real, desejos, sentimentos e pensamentos são apenas aspectos diferentes. As questões que devemos direcionar para a filosofia não podem ser respondidas através da afirmação de um $a$ priori epistemológico rígido, mas apenas através do desenvolvimento de um procedimento histórico fundamentado na totalidade de nosso ser. (Dilthey,1989, p. 51).

Desta forma, a experiência humana é vista como formada por vivências - experiências de caráter histórico, e por isso, toda ciência, inclusive a filosofia, deve referir-se à experiência. Essa concepção aponta para o fato de Dilthey considerar o objeto das ciências humanas como imediatamente dado, ou seja, é primeiro experimentado na consciência antes que tenhamos qualquer conhecimento científico sobre o mesmo: seria uma compreensão intuitiva da vida cotidiana e que permite um acesso não problemático às vivências da experiência humana. Com isto, Dilthey considera que as ciências humanas acessam seu objeto de estudo através da percepção interna dos "nexos da vida". 
São, portanto, três os aspectos do nexo psíquico: pensamento representado, sentimento e desejo. Não são funções individuais separáveis ou capacidades, mas são os constituintes da vida psíquica que estão contidos em cada estado singular de consciência. Ao invés de descrever a relação do mundo com o self como primeiramente representacional, que tende a fazer do mundo um construto ideal cuja realidade deve ser diferenciada, Dilthey mostra que tal relação teórica é derivada de uma relação experimental na qual o mundo é diretamente real num sentido prático e também teórico.

A insistência de Dilthey em fazer da experiência seu ponto de partida leva-o a um certo realismo. Sua abordagem psicológica da realidade da experiência procura revelar a totalidade e a complexidade da experiência e o faz repensar em termos práticos as atividades construtivas da consciência realçadas pelo idealismo. Embora qualquer experiência seja dada como um fato da consciência, Dilthey, também admite, em Introduction to the Human Sciences (1989, p. 69), que a experiência é governada por certas condições de consciência, as quais são introduzidas sucessivamente como pressuposições para a construção do mundo real.

Pode-se afirmar que, para Dilthey, a realidade independente do mundo externo é vivida diretamente, mas as estruturas objetivas do mundo devem ser construídas no processo histórico que testa as pressuposições da consciência. E, assim, a tarefa da filosofia não seria determinar as condições a priori do conhecimento de um modo ahistórico, mas sim refletir sobre as pressuposições em funcionamento no desenvolvimento histórico do conhecimento.

O contraste entre espírito e natureza, em Dilthey, se refere, portanto, aos esforços metafísicos anteriores para demarcar dois domínios em termos de duas substâncias. Historicamente, os esforços para delinear as ciências naturais e as ciências humanas foram baseados na distinção epistemológica, como a de Locke, entre sensação e reflexão e, a de Kant, entre experiência interna e externa. A experiência interna poderia ser definida independentemente do sentido externo, contudo suas formações poderiam ser respostas para processos naturais. Isto significa que o conhecimento obtido através 
das ciências naturais é, no mínimo, relevante para as ciências humanas. Dilthey, então, parte, em seu delineamento preliminar das ciências humanas com base na epistemologia moderna, para estabelecer a relativa independência das ciências humanas em face das bem estabelecidas ciências naturais.

No lugar de primeiramente orientar a experiência interior para um mundo exterior fenomenal, como Kant fazia, Dilthey orientava para uma estrutura de vida mais próxima da qual o mundo externo é derivado. Ele se esforçava para provar que as ciências humanas têm um status primordial em comparação com as ciências naturais, dentro do qual ele retêm uma relação mais próxima com o "nexo da vida" original de nossa experiência. Aqui a distinção que Dilthey estabeleceu entre "Wissen" e "Erkennen", conhecimento imediato e conhecimento conceitual, é importante. No segundo conceito, as ciências humanas continuariam dependentes das ciências naturais, mas no conhecimento imediato - no nível pré-reflexivo -, as ciências humanas ganhariam vantagem.

Além da tarefa de delimitar as ciências humanas com relação às ciências naturais, Dilthey também levanta uma questão de coerência interna das primeiras. Ele parte do fato de que não existe qualquer ordem construtiva entre as ciências humanas como existe entre as ciências naturais. Esse não desenvolvimento de tal sistema construtivo nas ciências humanas, pode ser explicado, em parte, pela sua gênese histórica. Elas devem sua existência à práxis da vida e sua organização deriva de necessidades práticas das profissões na vida moderna. Assim, também, os materiais históricos estudados pelas ciências humanas são transmitidos sob condições que refletem interesses de tipos muito heterogêneos.

Ainda nesta primeira fase, em que Dilthey desenvolve suas reflexões para o livro "Introduction to the Human Sciences" (1883), um elemento central de sua concepção é o fato de que não pode haver nenhuma ciência humana totalitária. Cada ciência humana particular é parcial e dependente das outras. Mesmo a psicologia, a ciência dos indivíduos, que são os elementos básicos da história e da sociedade, abstrai seus problemas subjetivos particulares de um amplo contexto da realidade social-histórica. 
Nesta visão, a sociedade é muito complexa para se compreender todo seu funcionamento, mas com base na experiência vivida das forças que a movem, pode-se compreender a vida social. Experiência vivida e compreendida estão diretamente ligadas sem referências explícitas às funções mediativas das expressões, que caracterizarão suas últimas reflexões. A sociedade não pode ser estudada por meio de uma ciência única, mas deve, ao contrário, ser abordada através de uma série de ciências sociais positivas, cada uma focando numa esfera diferenciada da vida social.

Observe-se que Dilthey não é o tipo de pensador para quem a história é entendida meramente em termos dos motivos e ações de indivíduos. Ele reconhece a necessidade de se trabalhar na direção de forças sociais já existentes, em contextos mais específicos delineados pela etnologia e pelos sistemas culturais, assim como também, da organização externa da sociedade. Ao invés de procurar uniformidades ou leis que atravessem o conjunto da história humana ou toda a sociedade, como a filosofia especulativa de Hegel da história e a sociologia de Comte fizeram, Dilthey procura “(...) uniformidades aplicáveis a fatos mais simples dentro dos quais nós podemos analisar o complexo mais alto do mundo social-histórico" (Makkreel \& Rodi, 1989, p. 19).

Dessa forma, a questão básica da discussão de Dilthey sobre a metafísica está ligada às categorias de "substância" e "causalidade", aplicando-as em relação a eventos naturais e à vida sócio-histórica. Para ele essas categorias não são abstrações aristotélicas de qualidades objetivas da realidade externa, nem relações formais kantianas projetadas pela mente, mas são derivadas de nossa própria experiência de vida (Makkreel \& Rodi,1989, p. 21).

A vida ou "nexos-vida" é apreendida pela própria consciência através de duas experiências básicas. A primeira é uma experiência de constância, apesar de todas as mudanças no nosso estado e nas nossas ações. É chamada de "auto-identificação" (selfsameness). A segunda, é a experiência de uma realidade que age no self, mas a qual sofre também a ação do self. É chamada de "ação e padecimento" (acting and suffering). De acordo com Makkreel \& Rodi (1989, p. 
21), Dilthey via a experiência fundamental de "selfsameness" e "acting e suffering" como sublinhando as categorias de "substância" e "causalidade". Essas últimas vistas como abstrações da totalidade do "nexos-vida," nas quais essas experiências constantemente ocorrem.

Assim, as categorias reais de selfsameness e acting and suffering seriam as expressões primeiras do nexos-vida e só depois esses conceitos de vida passariam através de um processo de abstração. Esse nexos-vida concretamente experimentado seria o esquema para a apreensão da totalidade vivida e real. Desse modo, verifica-se que, para Dilthey, aplicar conceitos da vida biológica para explicar a vida humana ou idéias hipotéticas sobre organismos para explicar relações sociais, é inverter a verdadeira ordem das coisas.

Contudo, Dilthey parece indicar que ambas, ciências naturais e humanas, têm suas origens no nexos-vida. É no nexos-vida, como dado na totalidade de nossa consciência, que o mundo externo produz sua realidade sentida, por sua resistência ao nosso desejo. Isso significa que, do ponto de vista de Dilthey, as ciências naturais são mais derivativas do que as ciências humanas. $\mathrm{O}$ mundo das ciências humanas preserva a realidade do nexos-vida em um sentido prático; o mundo das ciências naturais torna-se um construto fenomenal. Esse uso do nexos-vida como uma base comum para ambas, ciências naturais e humanas, antecipa o uso de Husserl do termo "mundo da vida" com o mesmo propósito. Para Dilthey (1989, p. 59), o sucesso da explicação nas ciências naturais é dúbio com sua exclusão de tudo que não é mensurável, o que levaria as relações funcionais a tomarem o lugar das categorias metafísicas de substância e causalidade. Portanto, o que Dilthey chama de "sistema natural das ciências humanas" aproxima-se do que teria sido desenvolvido, sobretudo, por Hume com base em modelos matemáticos. Este último, em seu programa, eliminaria a intencionalidade da categoria de causalidade nas ciências humanas. Observe-se que o ponto fundamental não é o uso do conceito de intencionalidade de modo especulativo como na metafísica, mas preservá-la como uma experiência interior. Se um sentimento de intencionalidade na ação é parte de nossas experiências, então a categoria de intenção não poderia ser eliminada das ciências humanas como tem sido nas ciências naturais. 
Para Dilthey (1989, p. 59), a construção metafísica das categorias tem provado ser de valor restrito e limitado. Todavia, a metafísica em si mesma aponta para certas experiências "meta físicas" fundamentais que são eternas. A metafísica como uma ciência está morta, mas permanecem "aspectos metafísicos de nossas vidas como experiência pessoal", que a arte e a literatura devem continuar expressando. A Filosofia não pode mais construir sistemas metafísicos, mas deve refletir sobre nossa disposição metafísica indestrutível em termos de uma análise das visões do mundo.

Dilthey afirma, portanto, que o nexos que envolve os fatos da consciência está contido na totalidade da vida psíquica. É preservando essa ligação entre cada ato do conhecimento e todo seu contexto, chamado nexos-vida, que a realidade de todo fato da consciência pode ser estabelecida. Quando visto sob a luz desse segundo princípio, o princípio inicial da fenomenologia dos fatos do conhecimento tornam-se princípios da realidade da vida psíquica. Fatos do conhecimento se tornam meros fenômenos apenas quando divorciados de todo nexos-vida, como Erlebnisse (experiência de vida) eles são reais.

As idéias de Dilthey já apontavam, também, para a importância da consciência reflexiva - esse sentimento de si próprio que precede a consciência de si e que é sempre ligado com uma consciência do mundo exterior, mesmo que essa consciência possa ser imperceptível. Seria uma consciência proto-intencional uma vez que é sempre orientada na direção do mundo, mesmo que o mundo não tenha sido, ainda, tematizado como objetivo. Ação e conteúdo coexistem como dois momentos irredutíveis. A ação não posiciona seu conteúdo nem coloca um conteúdo contra o sujeito como na consciência representacional. O self não é um dado imediato da consciência, mas o produto do nexos-vida da consciência, ambos temporalmente e espacialmente. O self de Dilthey participa na realidade do mundo espacial, mas, mais importante, o tempo, a forma da percepção interior, define a realidade do self.

Para Dilthey, o tempo é dado na totalidade de nossa própria consciência e não é meramente um fato do intelecto. Kant modelou 
sua visão do tempo na do espaço, e tratou ambos, tempo e espaço, como formas ideais para fenômenos intuitivos. Dilthey aceita amplamente a análise kantiana de que o espaço é uma forma ideal de nossa percepção externa dos objetos fenomenais. Contudo, rejeita a afirmação paralela de que o tempo é uma forma ideal da percepção interior. Uma vez que a percepção interior não é fenomenal como a percepção exterior, mas real - consistindo de fatos da consciência os quais são indubitáveis - o tempo deve ser também real.

É preciso compreender-se que o self não é o ponto de partida da teoria do conhecimento de Dilthey, mas o resultado de um processo de diferenciação no qual o nexos-vida da consciência é dividido em dois pólos - self e mundo. Aqui Dilthey antecipa George Herbert Mead, que, segundo Makkreel \& Rodi (1989, p. 29), casualmente, assistiu as palestras de Dilthey sobre ética e história da filosofia em 1890 e 1891.

O elemento crucial nesse processo de diferenciação do self e mundo é a consciência reflexiva acompanhando atos de desejo. É através da relação entre eficácia e resistência que aprendemos a distinguir a realidade da percepção interior da percepção exterior. Consciência reflexiva do desejo nos dá acesso a uma realidade que resiste ao nosso desejo e é reconhecida como independente de nós. Essa relação dinâmica com o mundo externo é mais fundamental do que a relação epistemológica estática da representação do objeto.

A epistemologia tradicional das ciências naturais tem feito nossa relação prática com o mundo parecer derivada da relação teórica e ignora nosso acesso original à realidade através da consciência reflexiva. Mais uma vez, os caminhos de Dilthey nos levam a concluir que a epistemologia das ciências humanas deve reclamar esse acesso e, assim, não pode ser meramente uma extensão de epistemologia das ciências naturais.

Após 1886, Dilthey acrescentou a categoria de "essencialidade" às de "substância" e de "causalidade". Ele trata as categorias de substância, causalidade e essencialidade em Berlin Lectures on Logic and Epistemology (1893), mostrando que cada 
uma delas é derivada a partir de como as experiências interiores informam nossa experiência exterior. Deste prisma, ele tenta distinguir definitivamente as ciências humanas das ciências naturais. Ele critica Kant, Leibniz e outros que apelam para um inconsciente sobre as bases de uma distinção entre percepção - não percepção. Ao valorizarem as percepções inconscientes e sobrevalorizarem as não percepções conscientes controladas pelo entendimento, esses pensadores criaram uma separação entre sentido e intelecto que Dilthey acha problemática. Seu argumento das operações lógicas elementares insiste sobre a intelectualidade nos níveis mais baixos da percepção (Makkreel \& Rodi, 1989, p. 35).

Isto significa dizer que os estados de consciência não são sempre acompanhados pela iluminação da consciência reflexiva. É possível ter estados que são conscientes, mas que não foram observados atenciosamente. Quando se presta atenção a algo, a consciência que se direciona para as coisas ao redor é diminuída. Dessa forma, enquanto a observação determinada da consciência pode ser apenas unidirecional em qualquer dado tempo, a consciência reflexiva em sua indeterminidade pode ser multidirecional.

A consciência é concebida como um continuum onde nenhum contexto pode ser entendido isolado de seu contexto maior. Para as ciências humanas este contexto é a experiência interior, para as ciências naturais é a experiência exterior. Experiência interior não se expande a partir do mundo, mas é o sistema de percepções de um self que pode envolver todas as percepções das coisas no mundo, assim como o modo como elas são apreendidas. Dilthey dá o exemplo do quadro de Goethe que está em sua sala, pois quando ele olha sente a sensação de prazer que sentia quando estava na sala de seu pai. Assim, esta é uma percepção que retêm sua referência do nexos-vida no qual ele foi experimentado inicialmente. A percepção interior é mais primordial do que a exterior.

O caráter controverso da distinção interna-externa se manifesta no primeiro esforço de Dilthey para definir o conhecimento de outras pessoas em termos das "conexões de percepção interna e externa". A experiência externa é comparada com a testemunha de outra pessoa 
caindo em lágrimas/pranto, e a experiência interna com minha própria capacidade de sentir dor ou pesar. $\mathrm{O}$ reconhecimento de que as lágrimas dos outros expressam a sua dor ou pesar pode ser descrito como uma inferência pela analogia: minhas lágrimas são precedidas de dor e pesar, então, as lágrimas dele devem também ser precedidas de dor e pesar. Contudo, Dilthey não está satisfeito com esse modelo de inferência. E acaba qualificando a inferência tradicional por analogia quando ele admite que ela é inadequada simplesmente para relacionar um estado singular da mente com uma expressão singular do corpo.

Compreender, então, torna-se menos um processo de relação entre interno e externo, num sentido estreito herdado, e mais um processo de relação da experiência interna como um conjunto, envolvendo a experiência externa como um de seus aspectos. Aqui temos a concepção de Dilthey de compreensão do significado das coisas em termos do contexto.

Em Introduction to the Human Sciences (1883), a interpretação permanece principalmente psicológica porque o nexos-vida é assumido como sendo centrado no nexos-vida psíquico. Enquanto Dilthey reconhece o modo como a vida psíquica é condicionada pelo ambiente, ele observa a psique individual como uma unidade relativamente independente. Os sistemas culturais, que derivam da linguagem, as artes e as ciências da economia e os sistemas legais são estabelecidos porque os indivíduos não podem atingi-los por eles mesmos. Nascemos em muitas associações, tais como a família e o governo, que não escolhemos, mas nenhuma pode determinar completamente a vida psíquica.

Para Dilthey, há apenas um questão genuinamente histórica: a psique individual. Ele examina como os sistemas culturais e a organização externa da sociedade estão em intersecção com as questões individuais. Em Introduction to the Human Sciences (1883) ele ainda não tem uma maneira conceitual de conceber a natureza dessa intersecção que não seja em termos gerais. Isto fica claro quando ele fala da linguagem como um sistema cultural, no qual as relações recorrentes da experiência interna são singularizadas pelo processo de articulação e formam categorias lingüísticas. 
Assim, Dilthey não chega a elaborar a articulação lingüística e assume, simplesmente, que as descrições psicológicas da consciência vão esclarecer as articulações gerais já encontradas nas análises prédiscursivas da consciência e do nexos-vida. A tarefa da psicologia como a primeira das ciências humanas seria produzir um auto entendimento que explique o que já é evidente na experiência interna. Hodges (1972, p. 186) descreve este método, o Narcherleben, como sendo um procedimento segundo o qual "nós entendemos uma expressão re-experimentando, na nossa própria consciência, a experiência a partir da qual esta expressão se originou”.

Na medida em que Dilthey muda de foco, da psicologia individual para a hermenêutica, introduz os termos "interpretação" e "exegese" para se referir à coordenação de atos elementares de entendimento os quais são necessários se as idéias, propósitos e outros estados mentais expressos nas formas complexas e duradouras do mundo construído na mente devem ser identificados. Formas culturais e instituições sociais, então, são interpretáveis como "expressões" da mente; os produtos da mente, se trabalhos literários ou instituições, são textos que tem de ser lidos e isto leva à hermenêutica para especificar os métodos a serem utilizados, apesar dos problemas colocados pelo círculo hermenêutico.

Dilthey percebeu, assim, que o reexperimentar não é, certamente, uma reprodução perfeita da experiência original; ela é esquemática, incompleta e falível. Ele distinguiu diferentes tipos de expressões e diferentes graus de exatidão e confiança com os quais elas podem ser interpretadas.

E, considerando a arte de compreender expressões como o fator básico comum a todas as Geisteswissenschaften, ele mostrou que há uma transição fácil da experiência pessoal para a autobiografia, dali para os escritos biográficos e históricos, dali para estudos mais abstratos e generalizáveis e disciplinas mais distintas e, finalmente, para a grande síntese na história do mundo.

A importância atribuída à dimensão cultural da vida, levou Dilthey a pensar Verstehen ou compreensão como uma metodologia 
que permitiria a reconstrução do processo de exteriorização (objetivação) da atividade humana, sem que fosse fundamental a reconstrução das experiências vivenciadas. Ele passa, então, a se concentrar nas estruturas de exteriorização da atividade humana e, com isto, a oposição mente $\mathrm{x}$ natureza passa de filosófica para mais claramente metodológica, concebendo um método objetivo no sentido de que o intérprete teria uma situação privilegiada frente aos atores originais, produtores de significados, pois ele teria acesso a um todo já constituído e a compreensão daquilo que transcende as relações individuais, mas que não teria um corresponde perfeito na realidade, algo que transcende a situação particular do intérprete - os sistemas culturais.

Entretanto, como discutiremos na seqüência, Gadamer (1998, p. 343) considera que essa passagem da base psicológica para uma hermenêutica das "ciências do espírito" não se efetivou com Dilthey, pois teria deixado sem solução questões relacionadas com a objetividade do método hermenêutico e, ainda, quanto ao modo de se ter acesso a este "espírito objetivo" antes dele se manifestar.

\section{Considerações finais}

Os estudos filosóficos e epistemológicos de Dilthey sobre o processo de objetivação da atividade humana foram importantes na caracterização das ciências humanas como ciências interpretativas, sobretudo, em disciplinas ligadas à história, à educação, à filosofia das ciências, dando margens às interpretações holistas, no sentido associado ao conceito hegeliano de "espírito objetivo", mas também às investigações ligadas à fenomenologia de Husserl, além das fundamentadas em Heidegger.

Diante disto, nestas considerações finais, serão discutidas algumas das principais críticas às idéias de Dilthey e contribuições para o debate contemporâneo sobre as formas de conhecimento nas ciências humanas e nas ciências naturais.

Weber, por exemplo, contemporâneo de Dilthey, segue um percurso teórico de questionamento da "causalidade objetiva", mas 
que de certa forma procurou inverter o método compreensivo de Dilthey, buscando libertá-lo de uma postura que qualificou de muito devedora à psicologia, ligada, sobretudo, à "experiência", à "vivência". Para Weber, compreender não significava ser co-autor de obras do passado através de um processo de empatia - como em Dilthey -, mas captar a "conexão de sentido" da ação humana no conjunto de outras ações, numa situação histórico-social, tomando sempre a "ação racional" como a mais inteligível e levando em consideração, sempre, que a interação resultante não seria admitida senão em caráter hipotético (Weber, 1994, p. 5-10).

Outrossim, parece que Dilthey, apesar de suas críticas ao positivismo de Comte, aos escritos dos empiricistas ingleses e ao naturalismo do século XVIII, não se desfez do legado da Ilustração. Ortega Y Gasset (1983, p. 171) e Horkheirmer (1971), entenderam Dilthey como alguém não tão distante do positivismo. Para o primeiro, Dilthey estava preocupado em fazer ciência a partir do conhecimento advindo da experiência. Para o segundo, Dilthey se negou a tirar conclusões que o colocassem em aberta oposição à idéia da "ciência livre de valores".

Entretanto, deve-se estar atento ao fato de que Dilthey, mesmo que concordasse com o positivismo e com o empiricismo quando afirmavam que toda ciência deve "ir aos fatos" e que "todo conhecimento advém da experiência", seu entendimento destes postulados era singular, peculiar. Nos seus escritos notamos os fatos como objetos do conhecimento, somente fatos da consciência, sendo que a experiência considerada é sempre uma experiência interna. A experiência interna é, segundo ele, "total"; é um momento da vida anímica em que representações se forjam necessariamente conjugadas com sentimentos e volições. O encadeamento destas experiências, ou seja, a conexão das vivências, assume configurações determinadas e consubstancia a "estrutura da vida psíquica" de cada pessoa. Dessa forma, a estrutura psíquica não é algo rígido, com categorias fixas que se debruçam sobre a realidade; mas algo histórico, em constante transformação na sua relação com o meio. A estrutura psíquica em sua relação com o meio é, em última instância, a responsável pela 
origem e desenvolvimento das obras culturais. Para Dilthey, o caráter histórico das obras culturais e dos sistemas filosóficos advém do caráter histórico e relativo da própria vida anímica.

Porém, para além de todas as possibilidades de mudanças que apontavam na direção do relativismo e do ceticismo -, Dilthey entendia que havia um ponto fixo, que justificaria o uso do conceito de "natureza humana", que seria o fato de que é imanente à estrutura da vida psíquica uma função teleológica. Ou seja, nas suas transformações, a estrutura psíquica está sempre voltada para o trabalho de adequação para atingir fins de auto-preservação. A necessidade de auto-preservação coloca a estrutura psíquica, no seu relacionamento com o meio, na tarefa de produzir ações e pensamentos cada vez mais universais e válidos e, assim, a produzir filosofia, arte e religião.

Dilthey esteve, durante grande parte de sua obra, preocupado com a existência de dois campos distintos de conhecimento: as ciências da natureza e as "ciências do espírito". Por mais que ele tentasse estabelecer esta distinção, em sua teoria encontramos elementos que nos conduzem a refletir no sentido de aproximações uma vez que todos os fatos são fatos da consciência individual, pois em Dilthey não há nada na realidade que, para ser conhecido, não tenha que ser apreendido como "vivência psíquica". Então, ambos os campos científicos são produtos da consciência. É a estrutura da vida psíquica que no indivíduo possui uma "conexão teleológica da vida", um sentido interno, que organiza a realidade no conhecimento e lhe dá um sentido. Esta seria a forma como age a consciência que conhece em relação aos fenômenos naturais e humanos.

Autores como Hodges (1972) consideram que visões como a de Dilthey tenderiam, em última instância, para um ceticismo. Entretanto, suas idéias parecem apontar para o fato de que, nessas esferas onde os métodos empíricos podem ser aplicados, os quais incluem algumas seções de Geisteswissenschaften, as ciências naturais, as descobertas e os progressos reais podem ser feitos e há conhecimento objetivo. Porém, é no domínio dos julgamentos de valor e das atitudes da vida que ele sentiu que a relatividade é inescapável, mas também que a própria aceitação disto pode levar ao enriquecimento da vida muito mais do que à frustração. 
Deve-se considerar, ainda, que o conceito de experiência, a concepção de causalidade e a busca de uma objetividade para as ciências humanas, nos termos colocados por Dilthey, sugeriram muitas perspectivas ao debate filosófico desde a segunda metade do século $\mathrm{XX}$, como, por exemplo, Gadamer e sua hermenêutica filosófica ou, ainda, autores mais recentes como Giddens (1977) e Souza Santos (1989), preocupados em desenvolver esta abordagem metodológica da hermenêutica para as ciências humanas, sobretudo, na direção do surgimento das condições fundamentais para uma mudança de paradigmas nas ciências humanas.

Outro elemento retomado por Giddens (1977) e Santos (1989), é a idéia de um unitarismo epistemológico aberto que dê conta das especificidades das ciências sociais e que seria obtido através da superação da contradição neokantiana entre "Verstehen" (compreensão) e "Erklären" (explicação), uma espécie de compromisso dominante a que se chegou depois do colapso do consenso positivista. Para estes autores, as ciências, em geral, usam como modelo explicativo a causalidade - e esta é a dimensão possível do unitarismo epistemológico, embora eles a utilizem de maneiras distintas.

O mesmo tem sido feito com relação aos conceitos de explicação e de compreensão, defendendo a complementaridade entre os dois modelos nos seguintes termos: uma explicação sem compreensão será aquela que se apresenta de forma estritamente naturalista, com mero recurso à causalidade e, por outro lado, uma compreensão sem explicação levaria em conta apenas o fundamento subjetivo da ação ou a sua evidência endopática. Giddens (1977) formula a necessidade dessa complementaridade em sua dupla hermenêutica e nas suas Novas regras do método sociológico.

Com efeito, os trabalhos de Dilthey são leituras fundamentais para a reflexão sobre as condições de produção do conhecimento nas ciências humanas. Na contemporaneidade, estas reflexões conduziram às abordagens que se fundamentam na impossibilidade de uma hierarquia mecânica entre as ciências humanas e naturais, embora a hegemonia das ciências humanas exprima-se em que seus modelos 
hermenêuticos serão cada vez mais usados pelas próprias ciências naturais e, por isso, a aproximação entre os dois universos científicos far-se-á no sentido das ciências humanas (o problema das relações entre ciência e ideologia ou o problema da conflitualidade interna). Portanto, mesmo havendo diferenças ônticas entre os objetos das duas ciências, o que as une é mais importante, no plano epistemológico, do que o que as separa.

Contudo, é relevante colocar-se que as questões relativas à "objetividade" do conhecimento nas ciências humanas foram, posteriormente, melhor trabalhadas pela hermenêutica filosófica de Gadamer, a partir de 1960, quando ele faz uma crítica da hermenêutica romântica e amplia a possibilidade de utilização, nas ciências humanas, de muitos dos conceitos analisados por Dilthey.

Em linhas gerais, pode-se dizer que Gadamer, embora mais influenciado pelas idéias de Heidegger do que por Dilthey, valoriza a contribuição de Dilthey não só por enfatizar as diferenças epistemológicas, entre explicar a ocorrência de eventos e compreender os significados, entre ciências naturais e ciências humanas, mas também por ter como ponto de partida a experiência interna do ser. A experiência interna individual como fundamento da compreensão histórica, uma certa homogeneidade entre sujeito e objeto como possibilidade do conhecimento histórico. Porém, Gadamer critica justamente o fato de que nessa condição de homogeneidade, o problema epistemológico permanecia ainda oculto, pois a pergunta que Dilthey se fez estava errada: não se tratava de questionar "como se eleva a experiência do indivíduo e seu conhecimento à experiência histórica" (Gadamer,1998, p. 341), ou seja, não se pode perguntar como as ciências do significado podem obter a objetividade característica das ciências naturais porque este padrão de objetividade é constituído dentro de certa tradição, apropriada para certos propósitos, mas não pode ser absolutizado como uma exigência em geral.

Desta forma, Gadamer (1998) faz uma crítica que não nega o ponto de partida de Dilthey, nem a importância da sua obra e da sua contribuição, dentro do momento histórico-cultural dos fins do século 
XIX, para a ampliação da hermenêutica como forma de conhecimento da sociedade e da história. Pode-se indicar que ele complementa estas reflexões e as amplia avaliando as condições de possibilidade da compreensão em geral, como fundamentadas numa tradição. A objetividade do conhecimento é, assim, reduzida por sua dependência da tradição, da história e essa dependência não pode ser transcendida por qualquer método. Em outras palavras, Gadamer retira o debate do plano epistemológico e o amplia em termos filosóficos, segundo uma concepção dialógica do conhecimento: "Compreender (Verstehen) para Gadamer é antes de tudo chegar a um entendimento (Verständigung) com outros” (Warnke,1987, p. 4).

Quando Gadamer questiona se Dilthey realmente fez esta passagem da posição psicológica para a hermenêutica, o faz a partir do fundamento da idéia de universalidade com que a compreensão se apropria do mundo histórico pois, para Gadamer (1998, p. 348), Dilthey se enreda em nexos de problemas que o levam a uma proximidade, tão pouco desejada por ele, com o idealismo especulativo de Hegel, sobretudo, quando coloca que o homem na história é determinado fundamentalmente pela relação de individualidade e "espírito objetivo". Mas, Gadamer (1998, p. 360) considera, também, que Dilthey ao ter como ponto de partida "o nexo de vida e saber" como um dado originário, sua posição torna-se invulnerável ante toda objeção que se possa fazer ao "relativismo" histórico, a partir da filosofia.

Deste modo, Gadamer ao criticar um certo intencionalismo histórico, refere-se muito mais aos demais membros da "hermenêutica romântica" como Ranke e Droysen, do que a Dilthey. Considera que ao impor os princípios hermenêuticos sobre o estudo da história, transpondo os conceitos diretamente da hermenêutica literária para o estudo da história humana, Ranke e Droysen ignoram a importância da própria imersão dos historiadores na história. Dilthey, ao contrário, reconhecia esta importância em seu esforço para encontrar as tensões entre a hermenêutica e uma abordagem apropriada à compreensão histórica, buscando a lógica da Geisteswissenschaften, ele teria reconhecido que esta diferença reside nos modos da experiência 
(Erlebnis) mais do que nos objetos da experiência. Ele teria partido de uma filosofia da vida (Lebensphilosophie), mas depois teria caído num objetivismo cartesiano ao supor que a legitimidade das ciências humanas (Geisteswissenschaften) seria alcançada através de sua fundamentação metodológica. Por isto, Gadamer considera importante diferenciar "experiência da vida" (Erlebnis) e "experiência científica” (Erfahrung).

E, finalmente, aponta-se para certos limites na obra de Dilthey, que precisam ser entendidos no contexto do debate maior no qual Dilthey se inseria. Porém, é importante ressaltar que a crítica de Gadamer (1998) a Dilthey, mais centrada em sua tendência a um cartesianismo epistemológico, pode ser vista como a mais importante e construtiva, podendo ser considerada, ainda, como complementar às análises filosóficas iniciadas por Dilthey. A questão da subjetividade-objetividade é central na discussão de Gadamer e, assim, a possibilidade de compreensão da sua crítica à hermenêutica do século XIX deve se dar mediante a análise dos desdobramentos do próprio conceito de comportamento subjetivo. Os desdobramentos parecem seguir um caminho que vai da concepção tradicional de hermenêutica - para a qual a 'subjetividade' significava uma abordagem individual, idiossincrática e arbitrária, contrastada com uma abordagem objetiva, a qual era treinada, disciplinada e metódica -, até a concepção de Gadamer, onde há o desejo de transcender a divisão subjetivo-objetivo, tomando como base a avaliação de Heidegger sobre a compreensão em sua obra Ser e Tempo (1975).

É preciso considerar-se, ainda, o aspecto de que o pensamento de Dilthey foi fortemente influenciado pelas idéias e teorias marcantes no século XIX e na transição para o século XX, os herdeiros da Ilustração. Pode-se dizer que ele preferiu dialogar com as correntes filosóficas como o kantismo e o positivismo de cunho empiricista inglês do que voltar-se, por exemplo, para os pensamentos alternativos provindos do ideário socialista.

\section{Notas}

1 É importante observar-se que foi na Alemanha, pelos herdeiros do historicismo do final do século XIX - ao qual pertenceu Dilthey -, que 
as polêmicas sobre a objetividade do conhecimento da realidade sóciohistórica determinaram mais diretamente a discussão sobre o procedimento metodológico das ciências sociais.

2 Para uma apreciação mais detalhada da concepção do problema da história universal para a chamada "escola histórica", em especial, em Ranke e Droysen, ver Gadamer (1998, p. 311-334).

Abstract: This article highlights the contribution of Wilheim Dilthey, part of the so-called German "romantic hermeneutics" movement, to contemporary human sciences, specially in relation to the search of the philosophical and epistemological foundations as a form of alternative scientific knowledge to 'positivist' and 'naturalist' knowledge. There are three main points. The first is the meaning of the terms 'Verstehen' (understanding) and 'Hermeneutics' from Dilthey's perspective. The second refers to the main concepts of his theory such as, for example, 'internal and external experience', 'causality' and 'understanding', identifying two phases in its comprehension of human action in which he passes from a stage marked by psychological comprehension to another, centred on a hermeneutic comprehension. In conclusion, we present some considerations on Dilthey's contribution to the social sciences and on Gadamer's central criticism of the way in which he sought objectivity for the human sciences. It is considered that the concept of experience, the concept of causality and the search of objectivity in the human sciences, in the terms expressed by Dilthey, posited various perspectives which have nourished the philosophical debate since the second half of the twentieth century, such as for example Gadamer and his philosophical hermeneutics, or more recent authors like Giddens (1977) and Souza Santos (1989), concerned with developing this methodological approach for the human sciences, specially in the sense of fostering the appearance of the fundamental conditions for a change in paradigms.

Key-words: hermeneutics, epistemology, experience, historical understanding, causality.

Résumé: Cet article rejaillit la contribution de Wilheim Dilthey dans l'herméneutique romantique alemande pour les sciences modernes, sourtout sa recherche des principes philosophiques e herméneutiques d'une sorte de conaissance scientifique alternatif à la conaissance "positiviste" et "naturaliste". Le départ s'appui sur trois point: le 
premier c'est la signification du terme "Verstehen" et "l'herméneutique" dans la perspective de Dilthey; le deuxième c'est les principaux concepts de sa théorie, par exemple: "expérience externe et interne" "causalitée" et "compréhension" en identifiant deux phases dans sa compréhension humaine, où il passe par une étape soulignée par la compréhénsion psicologique, l'autre centrée dans la compréhension herméneutique. Et pour finalisé sont tissée quelques considération sur la contribution de Dilthey pour les sciences sociales et sur la critique central de Gadamer et la façon comme il a cherché l'objetivitée pour les sciences humaines. C'est important considerer qui le concept de l'experiénce, la conception de causalitée et la recherche d'une objetivitée pour les sciences humaines de la façon que fait Dilthey ont suggeré plusieurs perspectives au débat philosophique depuis le moitié du XXe siécle, par exemple, Gadamer et sa herméneutique philoshopique, où encore des auteur plus récént comme Giddens (1977) et Souza Santos (1989), qui ont pour souci dévélopper cet abordage metodologique pour les sciences humaines, sourtout dans la diretion de l'aparition des conditions fundamentalles pour des changements paradigmatiques.

Mots-clés: herméneutique, epistemologie, éxperiénce, compréhension historique, causalitée.

\section{Referências bibliográficas}

COHN, G. Crítica e resignação: fundamentos da Sociologia de Max Weber. São Paulo: Queiroz, 1979.

DILTHEY, W. Introduction to the Human Sciences. Edited by R. A. Makkreel \& F. Rodi; trad. Michael Neville. New Jersey: Princeton University Press, 1989. (Selected Works, v. I).

GADAMER, H-G. Verdade e método: traços fundamentais de uma hermenêutica filosófica. Petrópolis, RJ: Vozes, 1998.

GIDDENS, Anthony. Structuration theory, empirical research and social critique. In: . The constitution of society. Cambridge: Polity Press, 1984. . New rules of sociological method. Londres: Hutchinson, 1977.

HAMLIN, Cynthia Lins. A hermenêutica romântica de Wilhelm Dilthey. Recife: UFPE, 1999. Mimeogr. 
HODGES, H.A. Wilhelm Dilthey. In: Sills (ed.) The International Encyclopaedia of the Social Sciences. Vol 3 and 4. New York: The MacMillan Company and the Free Press, 1972.

HORKHEIMER, M. Psicología y sociologia em la obra de Wilhelm Dilthey. In: Teoría crítica. Barcelona: Barral, 1971.

MAKKREEL, R. A.; RODI, F. Introduction. In: DILTHEY, W. Introduction to the Human Sciences. New Jersey: Princeton University Press, 1989. (Selected Works, v. I).

ORTEGA Y GASSET, J. Goethe - Dilthey. Madri: Alianza, 1983.

SANTOS, Boaventura de Souza. Introdução a uma Ciência Pós-Moderna. Rio de Janeiro: Graal, 1989.

WARNKE, Geórgia. Gadamer: hermeneutics, tradition and reason. Califórnia: Stanford University Press, 1987.

WEBER, Max. Economia e Sociedade: fundamentos da sociologia compreensiva. Brasília, DF: Editora da Universidade de Brasília, 1994. 
